\title{
1 Repair of Mismatched Templates during Rad51-dependent Break-Induced Replication
}




\section{Abstract}

Using budding yeast, we have studied Rad51-dependent break-induced replication (BIR), where the invading $3^{\prime}$ end of a site-specific double-strand break (DSB) and a donor template share 108 bp of homology that can be easily altered. When every $10^{\text {th }}$ base is mismatched between donor and recipient, BIR is $44 \%$ efficient compared to fully homologous sequences; but BIR still occurs about $10 \%$ when every $6^{\text {th }}$ base is mismatched. Here we explore the tolerance of mismatches in more detail, by examining donor templates that each carry 10 mismatches, but where they are clustered with spacings of every $6^{\text {th }} \mathrm{bp}$. These different arrangements of uneven mismatch distribution were in general less efficient in recombination as templates with evenly distributed mismatches. A donor with all 10 mismatches clustered every $6^{\text {th }}$ base at the $3^{\prime}$ invading end of the DSB was not impaired compared to the case where mismatches were clustered at the $5^{\prime}$ end. These data suggest that the efficiency of strand invasion is principally dictated by thermodynamic considerations, i.e., by the total number of base pairs that can be formed; but sequence-specific factors are also important. Mismatches in the donor template are incorporated into the BIR product in a strongly polar fashion up to $\sim 40$ nucleotides from the $3^{\prime}$ end. Mismatch incorporation depends on the $3^{\prime} \rightarrow 5^{\prime}$ proofreading exonuclease activity of DNA polymerase $\delta$, with little contribution from Msh2/Mlh1 mismatch repair proteins. Surprisingly, the probability of a mismatch $27 \mathrm{nt}$ from the $3^{\prime}$ end being replaced by donor sequence was the same whether the preceding 26 nucleotides were mismatched every $6^{\text {th }}$ base or fully homologous. These data suggest that DNA polymerase $\delta$ "chews back" the $3^{\prime}$ end of the invading strand without any mismatch-dependent cues from the strand invasion structure. 


\section{Author Summary}

DNA double-strand breaks (DSBs) are the most lethal forms of DNA damage and

37 inaccurate repair of these breaks presents a serious threat to genomic integrity and cell viability. Break-induced replication (BIR) is a homologous recombination pathway that results in a nonreciprocal translocation of chromosome ends. We used budding yeast Saccharomyces cerevisiae to investigate Rad51-mediated BIR, where the invading 3' end of the DSB and a donor template share $108 \mathrm{bp}$ of homology. We examined the tolerance of differently distributed mismatches on a homologous donor template and found that BIR efficiency was the same whether the mismatches were clustered at the $3^{\prime}$ invading end or at the $5^{\prime}$ end. We confirmed that mismatches are incorporated into the BIR product in a strongly polar fashion as far as

45 about 40 nucleotides from the $3^{\prime}$ end. We conclude that the proofreading activity of DNA polymerase $\delta$ "chews back" the 3 ' end of the invading strand even when the sequences removed have no mismatches for the first 26 nucleotides. These observations enrich our understanding of the details of Rad51-mediated strand invasion and provide insight into the mechanism of the $3^{\prime}$ to $5^{\prime}$ proofreading activity of DNA polymerase during homologous recombination.

\section{Introduction}

53 failure to repair these breaks can result in genome instability. Eukaryotes have evolved two

54 major types of DNA repair mechanisms to deal with DSBs: non-homologous end joining (NHEJ)

55 and homologous recombination (HR). In both "classic" NHEJ and in microhomology-mediated 
end-joining, broken ends are ligated back together, often using a small amount of

57 microhomology at the junction, frequently resulting in small insertions and deletions $[1,2,3,4]$.

HR by gene conversion relies on the resected ends of a DSB searching for and copying an intact

59

60

61

62

63

64

65

66

67

68

69

70

71

72

73

74

75

76 homologous sequence that serves as a template to accurately repair the lesion [5]. Two other

HR repair pathways - single-strand annealing (SSA) and break-induced replication (BIR) - also

rely on pairing with homologous sequences but often result in chromosome alterations [5].

BIR repairs DSBs that share only one end of homology with a donor sequence; such

events allow the extension of eroded telomeres and the re-initiation of DNA replication at

stalled and broken replication forks $[6,7]$. BIR is initiated by $5^{\prime} \rightarrow 3^{\prime}$ resection of a broken DNA

end to generate a $3^{\prime}$ single-stranded DNA (ssDNA) tail (Fig. S1A). Initially, replication protein

complex A (RPA) coats the ssDNA tails but is then displaced by the recombination protein,

Rad51 [8,9]. Each monomer of Rad51 and its bacterial homolog, RecA, binds 3 nucleotides of

ssDNA to form a nucleoprotein filament that catalyzes base-pairing and strand invasion

between the Rad51-coated ssDNA end of DSB and a homologous double-stranded DNA (dsDNA)

donor $[10,11,12,13]$. Strand invasion and the formation of a displacement loop (D-loop) enables

DNA polymerase $\delta$ to prime DNA synthesis and extend the $3^{\prime}$ end of invading strand to the end

of the chromosome $[14,15,16]$. In many respects, BIR events studied in budding yeast resemble

mammalian alternative lengthening of telomeres $(A L T)[7,17,18]$. BIR also appears to be critical

for DNA synthesis that occurs very late in the cell cycle as cells enter mitosis (MiDAS)

$[7,19,20,21]$. Both in yeast and in mammalian cells, the nonessential Pol32 (POLD3) subunit of

DNA polymerase $\delta$ is required for BIR but not for normal DNA replication $[22,23,24]$. 
Precisely how Rad51 performs strand exchange remains a subject of great interest

$[25,26,27,28]$. In budding yeast, efficient recombination by gene conversion (where both ends of the DSB interact with a donor template) requires a homologous region of about $70 \mathrm{bp}$ $[27,29]$. Rad51-dependent BIR also has similar homology length requirements. For example, in an intrachromosomal BIR assay (Fig. 1) in which a site-specific DSB is induced by the expression of $\mathrm{HO}$ endonuclease, approximately $14 \%$ of cells successfully repaired a DSB when the homologous region is $108 \mathrm{bp}$; but repair dropped to $1 \%$ with a 54-bp template and to $0.02 \%$ when there were only $26 \mathrm{bp}$ [24]. Repair is also reduced by the presence of heterologies (the presence of non-complementary bases between donor and recipient sequences), although even when every $6^{\text {th }}$ base was mismatched, BIR occurred at $10 \%$ of the rate when the templates were identical [24]. Repair efficiency was significantly reduced but still significant when every $6^{\text {th }}$ base was mismatched. These in vivo results contrast with in vitro single-molecule studies using very short substrates that found a minimum of at least 8 consecutive bases must be paired for a stable initial strand exchange mediated by RecA or Rad51 [10]. Another in vitro study concluded that 8 contiguous base pairs are required to tolerate up to a single mismatch in RecA-mediated strand exchange $[30,31]$. The differences among these studies may reflect the longer (108-bp) substrates used in our in vivo studies or the agency of other recombination proteins not presented in the in vitro studies.

Here, we extended our studies of mismatch tolerance by examining different templates with the same number of mismatches but distributed unevenly. We wished to determine if these different distributions would be treated equivalently, which would be the case if strand invasion in BIR were principally governed by thermodynamic considerations, in which the total 
99

100

101

102

103

\section{Results}

number of base pairs that can be formed dictates repair efficiency. We show that these different arrangements were in general less efficient than the evenly distributed mismatches, but exhibit significant differences that depend on the precise location of the mismatches. We show that this discrimination does not appear to be monitored by the Msh2-dependent mismatch repair system.

came from analyzing the assimilation of heterologies into the BIR product. Mismatches close to the $3^{\prime}$ end of the invading strand are almost invariably replaced by the template sequence, but there is a steep decline in their incorporation, so that by about $40 \mathrm{bp}$ from the $3^{\prime}$ end, incorporation of the template sequence is rare [24]. The assimilation of the template sequence is dependent on the $3^{\prime}$ to $5^{\prime}$ proofreading activity of DNA polymerase $\delta$, which presumably chews back the $3^{\prime}$ end of the invading strand before initiating copying of the donor template (Fig. S1B). There was little effect when Msh2/Mlh1-dependent mismatch repair was ablated, although the extent of mismatch assimilation was shortened [24]. Here, we make the surprising discovery that 3' to $5^{\prime}$ removal of the $3^{\prime}$ end of the strand-invading DNA is evident even when the first 26 nucleotides are completely homologous to the template, suggesting that this resection is not provoked by a nearby mismatch.

To study the effect of different distributions of mismatches on BIR repair efficiency we used the assay shown in Fig. 1. A galactose-inducible site-specific DSB is created by HO 
endonuclease at a site just distal to the $5^{\prime}$ end of the URA3 gene (UR) joined to an mRNA splicing donor sequence (SD) [24]. Only one end of the DSB shares homology with the donor, which in this case is located on the opposite arm of the same chromosome, about $30 \mathrm{~kb}$ from the telomere. The donor consists of a 108-bp region of homology such that the DSB end is perfectly matched to the donor (i.e., there are no additional nonhomologous sequences at the 3' end). The 108-bp homologous segment is adjacent to 3' splice acceptor (SA) site, followed by the $3^{\prime}$ end of the URA3 gene (A3). Thus, BIR results in a nonreciprocal translocation producing an intron-containing, intact URA3 gene so that cells can grow in the absence of uracil.

We confirmed our previous results [24] that strain yRA280 (with every $10^{\text {th }}$ base pair mismatched) and yRA321 (with every $6^{\text {th }}$ base pair mismatched) had reduced, but significant levels of repair (Fig. 2B) compared to yRA253 (a fully homologous donor). BIR was reduced to about $44 \%$ in yRA280 compared to yRA253, and still occurred about $9 \%$ in yRA321 (Fig. 2B). We then created six new strains, each of which had 10 mismatches, but arranged so that they were clustered every 6 bases apart (Fig.2A). The mismatches included both transversion and transition mismatches (Table 2).

The efficiency of BIR for the substrate with all mismatches clustered at the $3^{\prime}$ invading end of the DSB (Fig. 2C, donor template B) was similar to the reference yRA280, and was surprisingly more efficient than with a substrate with a 48 bp of perfect homology at the $3^{\prime}$ end (Fig. 2C, donor template D). Both template B and D were significantly different from reference strain yRA321, with every $6^{\text {th }}$ bp mismatched and 18 total mismatches (Fig. $2 \mathrm{C}$ ). Thus, although the $3^{\prime}$ end must be synapsed with the donor to allow DNA polymerase $\delta$ to initiate new DNA synthesis at the $3^{\prime}$ end, the efficiency of repair was not more impaired than with the 
142 mismatches all at the opposite end. These conclusions are generally supported by the results

143 using other mismatch spacings (Fig. 2A); but other substrates with 26 bp of perfect homology at

144 the $3^{\prime}$ end (Fig. 2C, donor templates E and F) yielded a significantly lower rate of successful

145 recombination when compared to yRA280 (Fig. 2C). The differences among these templates

146 cannot be attributed to a difference in thermal stability of base-pairing in the 108-bp region as

147 measured by the calculated melting temperature $(\mathrm{Tm})$ between complementary 108-nt DNA

148 strands (Table 2 and Fig. 3A). Interestingly, the correlation between BIR efficiency and Tm, seen

149 as the increasing frequency as a function of Tm, was nearly the same among the 6 unevenly-

150 spaced templates (dotted line, Fig. 3A) as for the evenly-spaced cases, but the correlation was

151 shifted to a lower average value (see Discussion). We note also that we did not find any

152 difference in the thermal stability of possible secondary structures that could be formed by the

153 different 108-nt regions, viewed as single-strand sequences (see Methods).

As we noted above, the $3^{\prime}$ end of the DSB is matched to the 108-bp template, with no nonhomologous 3' extension. Our previous studies have shown that even a short 3' extension

156 significantly reduces BIR repair, attributable to the role of the Msh2 mismatch repair protein in

157 triggering heteroduplex rejection [24]. We created a set of $m s h 2 \Delta$ derivatives of the set of

158 templates and found that the differences between the evenly-spaced mismatches and the

159 uneven cases were not suppressed (Fig. 3 and Fig. S2). However, the efficiency of BIR was

160 generally reduced relative to wild type, even for the case of no mismatches and the differences

161 between yRA280 and yRA321 was no longer statistically significant (Fig. S2). 
169 frequently replaced by the donor allele. There is a steep drop in assimilation, extending 40-50

170 nt from the DSB end, after which there was little or no incorporation of the mismatches (Fig.

$1714 \mathrm{E})[24]$.

173 sequenced approximately 50 BIR products from each of the templates shown in Fig. 2A. In each

174 case, mismatches were incorporated into the BIR product with the same strong polarity seen

175 with the evenly spaced mismatches [24]. Mismatch assimilation was seen as far as 55

176 nucleotides from the $3^{\prime}$ invading end (Fig. 4A, donor template B). For template D, containing 10

177 mismatches clustered near the $5^{\prime}$ end and with 48 bp perfect homology near the $3^{\prime}$ end of the

178 break, none of the 10 mismatches were incorporated (Fig. 4B, template D). However, for all the

179 constructs in which there were mismatches in the first $48 \mathrm{bp}$, the pattern of incorporation was

180 the same (Fig. 4E). Surprisingly, in donor templates E and F (Fig. 4C), the degree of

181 incorporation of mismatches at positions 27, 33 and 39 bp from the invading end was

182 indistinguishable from the correction of these same sites when all the mismatches are present

183 at the $3^{\prime}$ end (Fig. 4A, donor template B). These data suggest that $3^{\prime}$ to $5^{\prime}$ exonuclease activity of 
DNA polymerase $\delta$ removes the $3^{\prime}$ end of the invading strand to incorporate mismatches beyond 26 bp even when this region lacks any mismatches. and yRA321, as well as in donor template A (Fig. 5A). In each case, cells lacking MLH1 or MSH2 still can extend and correct mismatches $>30$ bp from the $3^{\prime}$ end of the DSB (Fig. 5A). There are no consistent differences between wild type, $m s h 2 \Delta$ and $m / h 1 \Delta$ strains; the differences in assimilation most likely reflect the limited number of sequences used to measure mismatch assimilation.

\section{$\underline{\text { Discussion }}$}

Although properties of budding yeast Rad51 have been well-studied in vitro

197 end of DSB and its donor templates share 108-bp homology, each carrying 10 mismatches, but

198 arranged in several different ways with a spacing of every $6^{\text {th }} \mathrm{bp}$. Donor templates that

199 clustered their mismatches near the 3' end, where strand invasion may begin (or at least must

200 be annealed before repair DNA synthesis can be initiated) were not impaired in their repair

201 compared to those with mismatches clustered at the $5^{\prime}$ end or in other arrangements. Overall,

202 these results demonstrate that the efficiency of repair is not strongly influenced by perfect

203 homology at the 3' end and further suggest that the success of repair is primarily a function of

204 the total number of base pairs that can be formed over the entire region. However, none of the 
arrangements of 10 mismatches with every $6^{\text {th }}$ base spacing was as efficient as a template with 10 mismatches, spaced every 10 base pairs, although in two cases the difference was not statistically significant. If the regions with many mismatches were not base-paired at all, we would expect to see BIR efficiencies comparable to the length of the remaining 54 bases in perfectly-matched sub-regions; however, we have previously shown that a template that had 54 perfectly matched base pairs (i.e. equivalent to the segments of the templates with no mismatches) yielded a BIR rate less than 7\% of a 108-bp region [24], whereas the efficiencies of the 6 templates we used were about $26 \%$ as successful (and where every $10^{\text {th }}$ was $44 \%$ ). So the regions containing mismatches every $6^{\text {th }}$ nucleotide must play a role in base-pairing, but there is a significant reduction in efficiency. This penalty is less than the very strong barrier seen from in vitro strand exchange studies $[10,30,31]$. The ability of Rad51 in vivo to deal with these highly mismatched regions could be explained by the presence of recombination factors in vivo that are not present in vitro. As shown in Fig. 3, the 6 templates with uneven mismatch spacing obey a similar temperature-dependence as the evenly-spaced controls; but the success of BIR is reduced (e.g. compare yRA280 and template F, which have almost the same Tm). We have not identified any sequence-specific or other properties of these sequences that can account for the reduced success of $B I R$, either in initiating recombination or in a later step. Further study will be needed to assess the relation of substrates with different Tm but the same number of base-pairs.

In these assays in which the 3' end does not have a nonhomologous extension, Msh2 does not provoke a reduction in repair through heteroduplex rejection [24]. Indeed, deleting Msh2 led to an overall reduction in repair efficiency for both the evenly- and unevenly-spaced 
227 templates so that any differences became statistically insignificant, but a similar correlation

228 with Tm persists. polymerase $\delta$ and its $3^{\prime}$ to $5^{\prime}$ proofreading activity. The pattern of mismatch incorporation into

231 the BIR product was the same at interior positions whether or not they were preceded by

232 mismatches nearer the $3^{\prime}$ end; that is, DNA Pol $\delta$ still backs up with $3^{\prime} \rightarrow 5^{\prime}$ exonuclease activity

233 to incorporate mismatches even when the first 26 positions are completely homologous. Thus,

234 proofreading at these interior positions is not dependent on any prior mismatch cues and

235 suggests that Pol $\delta$ intrinsically backs up on DNA templates even when they are fully

236 homologous. This activity is far more extensive than its apparent action in removing a single

237 mismatched base during DNA replication and is more comparable to the ability of Pol $\delta$ to

238 excise a $3^{\prime}$-ended nonhomologous segment at the end of a DSB being repaired by gene

239 conversion [32]; however, the pattern of mismatch assimilation is not compatible with an

240 intermediate in which an unpaired mismatched end would be excised as a $3^{\prime}$ flap, and the

241 incorporation of mismatches would be the same at each position. Deletion of MSH2 or MLH1

242 had no significant effect on the repair outcome.

We note that in meiosis, some gene conversion events appear to have involved a gap-

244 repair near the DSB $[33,34,35]$. However, one would find a similar pattern if Pol $\delta$ were to

245 resect the invading strand in a similar fashion during meiotic DNA repair.

\section{$246 \quad$ Methods}


248 yRA strains used in these experiments have the haploid S288c background (ho mat $\Delta$ ::hisG

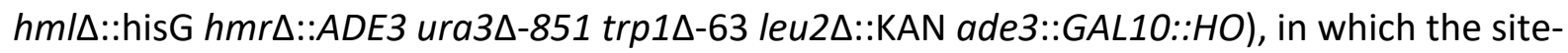
specific $\mathrm{HO}$ endonuclease is under control of a galactose-inducible promoter [36]. Strain yRA111 contains the recipient sequences composed of the $5^{\prime}$ sequences of URA3 gene (UR), an artificially inserted split-intron with the splice donor site (5' SD) and the HO recognition site (HOCS), located at the CAN1 locus in a non-essential terminal region of chromosome $\mathrm{V}$ [24]. Divergent donor sequences containing uneven distribution of mismatches were designed and ordered as synthetic gBlocks gene fragments from IDT and assembled into pRS314-based (CEN4, TRP1) plasmid containing the 3' splice-acceptor (3' SA) of the intron, the $3^{\prime}$ sequence

257 from the URA3 gene (A3) and the TRP1 marker (called bRA29 plasmid in this study) using in vivo 258 recombination and plasmid rescue from a yeast host strain as described in Anand et al. [24]. The donor cassettes were PCR-amplified from plasmid bRA29 and integrated at the FAU1 locus, about $30 \mathrm{~kb}$ from the right end of on chromosome V. Further information for strains, recipients

261 (donors) and plasmids are found in Tables 1, 2, 3 and 4.

262 BIR assay

Selected strains were grown on YEPD ( $1 \%$ yeast extract, $2 \%$ bactopeptone, $2 \%$ dextrose) + ClonNAT $\left(100 \mathrm{uL} / \mathrm{mL}\right.$ final concentration) at $30^{\circ} \mathrm{C}$. Individual colonies from strains were picked and serially diluted 1000 -fold in double-distilled $\mathrm{H}_{2} \mathrm{O}$. Serial dilutions were plated on YEPD to obtain the total number of cells and on YEP-galactose (YEP-Gal) to measure the recombination-

267 dependent survivors after inducing $\mathrm{HO}$ endonuclease expression [36]. Cells were incubated at

$26830^{\circ} \mathrm{C}$ for $2-3$ days. Cells on YEP-Gal were then replica plated to plates lacking uracil, to count colonies that survived the break via BIR, and to Nourseothricin (NAT) plates, to count colonies 
270 which survived the break via nonhomologous end-joining (NHEJ) that alters the HO cleavage

271 site but retains the distal part of the left arm of chromosome V [3]. Ura- $\mathrm{NAT}^{+}$colonies, arising

272 by nonhomologous end-joining, arose at a frequency of approximately $0.5 \%$ of the total

273 number of colonies and are not reported for each assay.

$274 \quad$ DNA sequence analyses of the break repair junctions

275 Representative Ura ${ }^{+}$colonies that had repaired by BIR were confirmed by PCR, using primers

276 amplifying the region at the start and end of the URA3 gene using primers DG31

277 (GGAACGTGCTGCTACTCATC) and DG32 (TTGCTGGCCGCATCTTCTCA). PCR products were initially

278 checked by gel electrophoresis and sent to GENEWIZ for Sanger sequencing. Individual PCR

279 sequences were aligned with corresponding 108-bp donor templates and analyzed by DNA

280 analyses software Serial Cloner 2.6.1 and Geneious Prime software.

$281 \quad$ Statistical Analysis

282 GraphPad Prism 9 software was used to calculate statistical significance of data, based on

283 Dunnett's comparison of multiple samples versus a single control. Thermal stability, as reflected

284 in melting temperature $\operatorname{Tm}\left({ }^{\circ} \mathrm{C}\right)$. of the base-pairing between the DSB $3^{\prime}$ and a complementary

285 single strand of of the donor template was determined using the method of Markham and

286 Zuker, 2005 (http://www.unafold.org/Dinamelt/applications/two-state-melting-

287 hybridization.php) [37]. By using Geneious Prime’s DNA secondary structure fold viewer

288 (https://assets.geneious.com/manual/2021.1/static/GeneiousManualse36.html), we monitored

289 possible secondary structures of the donor templates. $\Delta \mathrm{G}$ of all donor templates were

290 calculated to determine the energy required to break the secondary structure. 


\section{Acknowledgements}

292 Funding: This work has been supported by the National Institute of Health grants R35

293 GM127029 to J.E.H D.N.G. has been supported by NIGMS Genetics Training Grant

294 T32GM007122 (https://www.nigms.nih.gov/) and by the National Science Foundation

295 Graduate Research Fellowship Program under grant 1744555 (https://www.nsfgrfp.org/).

296 Special thanks to Dr, Michael Lichten (National Cancer Institute Center for Cancer Research), Dr.

297 Stephen Levene (University of Texas at Dallas), Dr. Eric Greene (Columbia University), Dr. Myron

298 Goodman and Dr. Chiho Mak (University of Southern California) for discussions about this

299 research. 


\section{References}

302

303

304

305

306

307

308

309

310

311

312

313

314

315

316

317

318

319

320

321

322

323

324

325

326

327

328

329

330

331

332

333

334

335

1. Pfeiffer P, Goedecke W, Obe G. Mechanisms of DNA double-strand break repair and their potential to induce chromosomal aberrations. Mutagenesis. 2000; 15(4):289-302. doi: 10.1093/mutage/15.4.289. PMID: 10887207

2. Jasin $M$, Rothstein R. Repair of strand breaks by homologous recombination. Cold Spring Harb Perspect Biol. 2013; 5(11):a012740. doi: 10.1101/cshperspect.a012740. PMID: 24097900

3. Moore JK, Haber JE. Cell cycle and genetic requirements of two pathways of nonhomologous endjoining repair of double-strand breaks in Saccharomyces cerevisiae. Mol Cell Biol. 1996; 16(5):2164-2173. PMID:8628283

4. Boulton SJ, Jackson SP. Saccharomyces cerevisiae Ku70 potentiates illegitimate DNA double-strand break repair and serves as a barrier to error-prone DNA repair pathways. EMBO J. 1996; 15(18): 5093-5103. PMID:8890183

5. Haber JE. A Life Investigating Pathways That Repair Broken Chromosomes. Annu Rev Genet. 2016; 50:1-28. doi: 10.1146/annurev-genet-120215-035043. PMID: 27732795

6. Symington LS, Gautier J. Double-strand break end resection and repair pathway choice. Annu Rev Genet. 2011; 45:247-71. doi: 10.1146/annurev-genet-110410-132435. PMID: 21910633

7. Epum EA, Haber JE. DNA replication: the recombination connection. Trends Cell Biol. 2021; S09628924(21)00145-8. doi: 10.1016/j.tcb.2021.07.005. PMID: 34384659

8. Sung P. Function of yeast Rad52 protein as a mediator between replication protein $A$ and the Rad51 recombinase. J Biol Chem. 1997; 272(45):28194-7. doi: 10.1074/jbc.272.45.28194. PMID: 9353267

9. New JH, Sugiyama T, Zaitseva E, Kowalczykowski SC. Rad52 protein stimulates DNA strand exchange by Rad51 and replication protein A. Nature. 1998; 391(6665):407-10. doi: 10.1038/34950. PMID: 9450760

10. Lee JY, Steinfeld JB, Qi Z, Kwon Y, Sung P, Greene EC. Sequence imperfections and base triplet recognition by the Rad51/RecA family of recombinases. J Biol Chem. 2017; 292(26):11125-11135. doi: 10.1074/jbc.M117.787614. PMID: 28476890

11. Sung P. Catalysis of ATP-dependent homologous DNA pairing and strand exchange by yeast RAD51 protein. Science. 1994; 265(5176):1241-3. doi: 10.1126/science.8066464. PMID: 8066464

12. Petukhova G, Stratton S, Sung P. Catalysis of homologous DNA pairing by yeast Rad51 and Rad54 proteins. Nature. 1998; 393(6680):91-4. doi: 10.1038/30037. PMID: 9590697

13. Chen Z, Yang H, Pavletich NP. Mechanism of homologous recombination from the RecAssDNA/dsDNA structures. Nature. 2008; 453(7194):489-4. doi: 10.1038/nature06971. PMID: 18497818 
14. Mazin AV, Bornarth CJ, Solinger JA, Heyer WD, Kowalczykowski SC. Rad54 protein is targeted to pairing loci by the Rad51 nucleoprotein filament. Mol Cell. 2000; 6(3):583-92. doi: 10.1016/s10972765(00)00057-5. PMID: 11030338

15. Piazza A, Shah SS, Wright WD, Gore SK, Koszul R, Heyer WD. Dynamic Processing of Displacement Loops during Recombinational DNA Repair. Mol Cell. 2019;73(6):1255-1266.e4. PMID:30737186

16. Shinohara A, Ogawa $H$, Ogawa T. Rad51 protein involved in repair and recombination in $S$. cerevisiae is a RecA-like protein. Cell. 1992; 69(3):457-70. doi: 10.1016/0092-8674(92)90447-k. PMID: 1581961

17. Anand RP, Lovett ST, Haber JE. Break-induced DNA replication. Cold Spring Harb Perspect Biol. 2013; 5(12):a010397. doi: 10.1101/cshperspect.a010397. PMID: 23881940

18. Roumelioti FM, Sotiriou SK, Katsini V, Chiourea M, Halazonetis TD, Gagos S. Alternative lengthening of human telomeres is a conservative DNA replication process with features of breakinduced replication. EMBO Rep. 2016; 17(12):1731-1737. doi: 10.15252/embr.201643169. PMID: 27760777

19. Bhowmick R, Minocherhomji S, Hickson ID. RAD52 Facilitates Mitotic DNA Synthesis Following Replication Stress. Mol Cell. 2016; 64(6):1117-1126. doi: 10.1016/j.molcel.2016.10.037. PMID: 27984745

20. Minocherhomji S, Ying S, Bjerregaard VA, et al. Replication stress activates DNA repair synthesis in mitosis. Nature. 2015; 528(7581):286-90. PMID: 26633632

21. Ji F, Liao H, Pan S, et al. Genome-wide high-resolution mapping of mitotic DNA synthesis sites and common fragile sites by direct sequencing. Cell Res. 2020; 30(11):1009-1023. PMID: 32561861

22. Lydeard JR, Jain S, Yamaguchi M, Haber JE. Break-induced replication and telomerase-independent telomere maintenance require Pol32. Nature. 2007; 448(7155):820-3. doi: 10.1038/nature06047. PMID: 17671506

23. Simon M, Giot L, Faye G. The 3 ' to $5^{\prime}$ exonuclease activity located in the DNA polymerase delta subunit of Saccharomyces cerevisiae is required for accurate replication. EMBO J. 1991; 10(8):2165-70. PMID: 1648480

24. Anand R, Beach A, Li K, Haber J. Rad51-mediated double-strand break repair and mismatch correction of divergent substrates. Nature. 2017; 544(7650):377-380. doi: 10.1038/nature22046 PMID: 28405019

25. Bell JC, Kowalczykowski SC. Mechanics and Single-Molecule Interrogation of DNA Recombination. Annu Rev Biochem. 2016; 85:193-226. doi: 10.1146/annurev-biochem-060614-034352. PMID: 27088880

26. Wu Y, Kantake N, Sugiyama T, Kowalczykowski SC. Rad51 protein controls Rad52-mediated DNA annealing. J Biol Chem. 2008; 283(21):14883-92. doi: 10.1074/jbc.M801097200. PMID: 18337252

27. Ira G, Haber JE. Characterization of RAD51-independent break-induced replication that acts preferentially with short homologous sequences. Mol Cell Biol. 2002; 22(18):6384-92. doi: 10.1128/mcb.22.18.6384-6392.2002. PMID: 12192038 
401

402

403

404

405

406

407

408
28. Van Komen S, Petukhova G, Sigurdsson S, Stratton S, Sung P. Superhelicity-driven homologous DNA pairing by yeast recombination factors Rad51 and Rad54. Mol Cell. 2000; 6(3):563-72. doi: 10.1016/s1097-2765(00)00055-1. PMID: 11030336

29. Mehta A, Beach A, Haber JE. Homology Requirements and Competition between Gene Conversion and Break-Induced Replication during Double-Strand Break Repair. Mol Cell. 2017; 65(3):515526.e3. doi: 10.1016/j.molcel.2016.12.003. PMID: 28065599

30. Danilowicz C, Yang D, Kelley C, Prévost C, Prentiss M. The poor homology stringency in the heteroduplex allows strand exchange to incorporate desirable mismatches without sacrificing recognition in vivo. Nucleic Acids Res. 2015; 43(13):6473-85. doi: 10.1093/nar/gkv610. PMID: 26089391

31. Lee JY, Terakawa T, Qi Z, et al. DNA RECOMBINATION. Base triplet stepping by the Rad51/RecA family of recombinases. Science. 2015; 349(6251):977-81. doi: 10.1126/science.aab2666. PMID: 26315438

32. Colaiácovo MP, Pâques F, Haber JE. Removal of one homologous DNA end during gene conversion by a RAD1- and MSH2-independent pathway. Genetics. 1999;151(4):1409-23 PMID: 10101166

33. Ribeiro J, Abby E, Livera G, Martini E. RPA homologs and ssDNA processing during meiotic recombination. Chromosoma. 2016; 125(2):265-76. doi: 10.1007/s00412-015-0552-7. PMID: 26520106

34. Prieler S, Penkner A, Borde V, Klein F. The control of Spo11's interaction with meiotic recombination hotspots. 2005;19(2):255-69. doi: 10.1101/gad.321105. PMID: 15655113

35. Keeney S, Neale MJ. Initiation of meiotic recombination by formation of DNA double-strand breaks: mechanism and regulation. Biochem Soc Trans. 2006; 34(Pt 4):523-5. doi: 10.1042/BST0340523. PMID: 16856850

36. Sandell LL, Zakian VA. Loss of a yeast telomere: arrest, recovery, and chromosome loss. Cell 1993; 75(4):729-39 PMID: 8242745

37. Markham NR, Zuker M. DINAMelt web server for nucleic acid melting prediction. Nucleic Acids Res. 2005;33:W577-81 PMID: 15980540 doi: 10.1093/nar/gki591 
411 The recipient sequence shares the 108-bp region of homology and contain the $5^{\prime}$ sequences

412 from the URA3 gene (UR), the splice donor site (5' SD) of an artificial intron and the HO cut site.

413 108-bp donor sequences containing different mismatch distributions were assembled into a

414 plasmid containing the $3^{\prime}$ sequences from the URA3 gene (A3), the 3' splice-acceptor ( $3^{\prime}$ SA) of

415 the intron and the TRP1 auxotrophic maker. A DSB was created using the galactose-inducible

$416 \mathrm{HO}$ endonuclease. This break is repaired by BIR using the donor sequences that share 108-bp of

417 homology located on the opposite arm of chromosome V. Once BIR is complete, a functional

418 intron is formed, and yeast become $\mathrm{Ura3}^{+}$recombinants.

Figure 2. The effect of different distributions of mismatches on a 108-bp donor template on the efficiency of Rad51-dependent BIR.

A. 108-bp donors with even mismatch distribution: yRA253 (no mismatch), yRA280 (10 mismatches every 10th) and yRA321 (18 mismatches every 6th). The set of donors with even

423 mismatch distribution was compared with a set of divergent 108-bp donor templates

424 containing a total of 10 mismatches that are distributed unevenly throughout the template. The

425 spacing between the clustered mismatches are every 6th bp. Specific sequences are shown in

426 Table 2. B. Percent BIR efficiency of 108-bp donors with perfect homology and even mismatch

427 distribution. Welch's t-test was used to determine the $p$-value, ${ }^{*} p \leq 0.001$, ns $=$ not significant.

428 Error bars indicate standard deviation. A minimum of three measurements were performed. C.

429 Percent BIR efficiency of 108-bp donors with even and uneven distribution. The set of donors 
with uneven mismatch distribution was compared to yRA280 which contains the same spacing between clustered mismatches. Significance determined using a Dunnett's method

433 (GraphPad Prism 9). Error bars refer to standard deviation. ${ }^{* *} \mathrm{p}<0.001$, ns $=$ not significant.

Figure 3. Rad51-mediated strand annealing is less efficient when the mismatches are spaced

445 Figure 4. DNA Pol $\delta$ still “backs up" to perform $3^{\prime} \rightarrow 5$ ' proofreading activity to incorporate

446 mismatches even if there are no mismatches closer to the $3^{\prime}$ end of DSB

447 A-D. Percent mismatch incorporation of individual donor templates containing 10 mismatches

448 distributed unevenly throughout the 108-bp donor template. E. Composite of \% mismatch 
Figure 5. The mismatch assimilation of the template sequence does not proceed through Msh2/Mlh1-dependent mismatch repair.

452 A. The effect of deleting mismatch repair gene $M S H 2$ or $M L H 1$ on mismatch incorporation

453 pattern and BIR efficiency for strains yRA280 and yRA321. B. The effect of deleting mismatch

454 repair gene $\mathrm{MSH} 2$ or $\mathrm{MLH1}$ on mismatch incorporation pattern and BIR efficiency for donor

455 template A. Welch's t-test was used to determine the p-value. Error bars refer to standard error

456 of the mean. A minimum of at least three measurements were performed $\mathbf{C}$. The effect of

457 deleting mismatch repair gene MSH2 on BIR efficiency for a set of divergent 108-bp donor

458 templates with uneven distribution. Significance determined using a Dunnett's method for

459 multiple comparisons. Error bars refer to standard error of the mean.

A. Mechanism of Rad51-dependent BIR B. Mismatch incorporation of heteroduplex DNA

462 formation during BIR. Once a DSB is created, a broken end of DSB will be resected by $5^{\prime} \rightarrow 3^{\prime}$

463 exonuclease to generate $3^{\prime}$ single-stranded DNA (ssDNA) which interact with several

464 recombination proteins to carry out homology search and strand invasion. Since both donor

465 and recipient sequence share a 108-bp homology, the broken and resected end of recipient

466 sequence (indicated in red) will find this homology and initiate strand invasion into donor

467 sequence (indicated in blue). Mismatches are created in the heteroduplex region during strand

468 invasion and polymerase $\delta$ get recruited to perform its proofreading $3^{\prime} \rightarrow 5^{\prime}$ exonuclease

469 activity. DNA Polymerase $\delta$ "backs up" into the heteroduplex region and resynthesizes the 
470 region in reference to donor templates to incorporate mismatches. BIR completes and results in

471 BIR products with mismatches close to the 3' end frequently being incorporated.

472 Figure S2. The effect of MSH2 mutants on the repair efficiency

473 Wild type and $m s h 2 \Delta$ derivatives of each donor template were measured as described in Fig. 1.

474 Statistical significance of the differences for each donor/msh2 $\Delta$ pair was determined using an

475 unpaired t-test with Welch's correction. Error bars refer to standard deviation. Each

476 measurement is based on a minimum of three experiments. 
Table 1. Yeast strains used in this study

\begin{tabular}{|c|c|c|}
\hline $\begin{array}{l}\text { Strain } \\
\text { Name }\end{array}$ & Strain Genotype & Strain Description \\
\hline yRA111 & $\begin{array}{c}\text { MATa::DEL HOcs::hisG ura-3D851 trp1-DEL63 } \\
\text { leu2DEL::KAN hmIDEL::hisG hmr::ADE3 ade3::GAL::HO } \\
\text { can1DEL::UR intron_SD::HOcs::NAT }\end{array}$ & $\begin{array}{l}\text { Donorless Strain } \\
\text { (Only contains the recipient) }\end{array}$ \\
\hline yRA253 & $\begin{array}{c}\text { MATa::DEL HOcs::hisG ura-3D851 trp1-DEL63 } \\
\text { leu2DEL::KAN hmIDEL::hisG hmr::ADE3 ade3::GAL::HO } \\
\text { can1DEL::UR intron_SD::HOcs::NAT, intron-SA-A3::TRP1 }\end{array}$ & $\begin{array}{l}\text { Perfect homology } \\
\text { (No mismatch) }\end{array}$ \\
\hline yRA280 & $\begin{array}{c}\text { MATa::DEL HOcs::hisG ura-3D851 trp1-DEL63 } \\
\text { leu2DEL::KAN hmIDEL::hisG hmr::ADE3 ade3::GAL::HO } \\
\text { can1DEL::UR intron_SD::HOcs::NAT, intron-SA-A3::TRP1 }\end{array}$ & $\begin{array}{l}10 \text { mismatches } \\
\text { every } 10^{\text {th }} \mathrm{bp}\end{array}$ \\
\hline yRA321 & $\begin{array}{c}\text { MATa::DEL HOcs::hisG ura-3D851 trp1-DEL63 } \\
\text { leu2DEL::KAN hmIDEL::hisG hmr::ADE3 ade3::GAL::HO } \\
\text { can1DEL::UR intron_SD::HOcs::NAT, intron-SA-A3::TRP1 }\end{array}$ & $\begin{array}{l}18 \text { mismatches } \\
\text { every } 6^{\text {th }} \mathrm{bp}\end{array}$ \\
\hline A & $\begin{array}{c}\text { MATa::DEL HOcs::hisG ura-3D851 trp1-DEL63 } \\
\text { leu2DEL::KAN hmIDEL::hisG hmr::ADE3 ade3::GAL::HO } \\
\text { can1DEL::UR intron_SD::HOcs::NAT, intron-SA-A3::TRP1 }\end{array}$ & $\begin{array}{l}10 \text { mismatches } \\
\text { (5 mismatches on both } 3^{\prime} \\
\text { and 5' end, 52bp perfect } \\
\text { homology in the middle) }\end{array}$ \\
\hline B & $\begin{array}{l}\text { MATa::DEL HOcs::hisG ura-3D851 trp1-DEL63 } \\
\text { leu2DEL::KAN hmIDEL::hisG hmr::ADE3 ade3::GAL::HO } \\
\text { can1DEL::UR intron_SD::HOcs::NAT, intron-SA-A3::TRP1 }\end{array}$ & $\begin{array}{l}10 \text { mismatches } \\
\text { (10 mismatches clustered on } \\
\text { 3'end, 53bp perfect } \\
\text { homology on 5'end) }\end{array}$ \\
\hline C & $\begin{array}{c}\text { MATa::DEL HOcs::hisG ura-3D851 trp1-DEL63 } \\
\text { leu2DEL::KAN hmIDEL::hisG hmr::ADE3 ade3::GAL::HO } \\
\text { can1DEL::UR intron_SD::HOcs::NAT, intron-SA-A3::TRP1 }\end{array}$ & $\begin{array}{l}10 \text { mismatches } \\
\text { (27bp perfect homology }-5 \\
\text { mismatches }-27 \text { bp perfect } \\
\text { homology }-5 \text { mismatches) }\end{array}$ \\
\hline D & $\begin{array}{c}\text { MATa::DEL HOcs::hisG ura-3D851 trp1-DEL63 } \\
\text { leu2DEL::KAN hmIDEL::hisG hmr::ADE3 ade3::GAL::HO } \\
\text { can1DEL::UR intron_SD::HOcs::NAT, intron-SA-A3::TRP1 }\end{array}$ & $\begin{array}{l}10 \text { mismatches } \\
\text { (10 mismatches clustered on } \\
5^{\prime} \text { end, } 48 \text { bp perfect } \\
\text { homology on 3' end) }\end{array}$ \\
\hline $\mathrm{E}$ & $\begin{array}{l}\text { MATa::DEL HOcs::hisG ura-3D851 trp1-DEL63 } \\
\text { leu2DEL::KAN hmIDEL::hisG hmr::ADE3 ade3::GAL::HO } \\
\text { can1DEL::UR intron_SD::HOcs::NAT, intron-SA-A3::TRP1 }\end{array}$ & $\begin{array}{c}10 \text { mismatches } \\
\text { (27bp and } 26 \mathrm{bp} \text { perfect } \\
\text { homology on both } 3^{\prime} \text { and } 5^{\prime} \\
\text { end, } 10 \text { mismatches in the } \\
\text { middle) }\end{array}$ \\
\hline $\mathrm{F}$ & $\begin{array}{c}\text { MATa::DEL HOcs::hisG ura-3D851 trp1-DEL63 } \\
\text { leu2DEL::KAN hmIDEL::hisG hmr::ADE3 ade3::GAL::HO } \\
\text { can1DEL::UR intron_SD::HOcs::NAT, intron-SA-A3::TRP1 }\end{array}$ & $\begin{array}{c}10 \text { mismatches } \\
\text { (5 mismatches }-27 b p \\
\text { perfect homology }-5 \\
\text { mismatches }-26 b p \text { perfect } \\
\text { homology) }\end{array}$ \\
\hline
\end{tabular}


Table 2. Recipient and donor sequences

\begin{tabular}{|c|c|c|}
\hline $\begin{array}{l}\text { Recipient } \\
\text { sequence }\end{array}$ & $\begin{array}{c}\text { Melting } \\
\text { Temperature } \\
\operatorname{Tm}\left({ }^{\circ} \mathrm{C}\right)\end{array}$ & $\begin{array}{l}\text { TAATATGGACTAAAGGAGGCTTTTCTGCAGGTCGATCTAAATAAATTCGTTTTCAA } \\
\text { TGATTAAAATAGCATAGTCGGGTTTTTCTTTTAGTTTCAGCTTTCCGCAACA }\end{array}$ \\
\hline $\begin{array}{c}\text { Perfect } \\
\text { homology } \\
\text { donor } \\
\text { (yRA253) }\end{array}$ & $89.0^{\circ} \mathrm{C}$ & $\begin{array}{l}\text { TAATATGGACTAAAGGAGGCTTTTCTGCAGGTCGATCTAAATAAATTCGTTTTCA } \\
\text { ATGATTAAAATAGCATAGTCGGGTTTTTCTTTTAGTTTCAGCTTTCCGCAACA }\end{array}$ \\
\hline $\begin{array}{c}\text { Mismatches } \\
\text { every } 10^{\text {th }} \\
\text { bp } \\
\text { (yRA280) }\end{array}$ & $80.6^{\circ} \mathrm{C}$ & $\begin{array}{l}\text { TAATATGGTCTAAAGGAGCCTTTTCTGCTGGTCGATCTTAATAAATTCCTTTTCA } \\
\text { ATGTTTAAAATAGGATAGTCGGGATTTTCTTTTTGTTTCAGCTATCCGCAACA }\end{array}$ \\
\hline $\begin{array}{c}\text { Mismatches } \\
\text { every } 6^{\text {th }} \text { bp } \\
\text { (yRA321) }\end{array}$ & $71.8^{\circ} \mathrm{C}$ & $\begin{array}{l}\text { AAATATCGACTATAGGAGCCTTTTGTGCAGCTCGATGTAAATTAATTCCTTTTCTA } \\
\text { TGATAAAAATTGCATACTCGGGATTTTCATTTAGATTCAGGTTTCCCCAACA }\end{array}$ \\
\hline $\begin{array}{l}\text { Donor } \\
\text { Template A }\end{array}$ & $83.5^{\circ} \mathrm{C}$ & $\begin{array}{l}\text { TAATAAGGACTCAAGGACGCTTTGCTGCAAGTCGATCTAAATAAATTCGTTTTCA } \\
\text { ATGATTAAAATAGCATAGTCGGGTTTTGCTTTTTGTTTCGGCTTTACGCAACC }\end{array}$ \\
\hline $\begin{array}{l}\text { Donor } \\
\text { Template B }\end{array}$ & $82.8^{\circ} \mathrm{C}$ & $\begin{array}{l}\text { TAATATGGACTAAAGGAGGCTTTTCTGCAGGTCGATCTAAATAAATTCGTTTTGA } \\
\text { ATGACTAAAACAGCATGGTCGGCTTTTTGTTTTAATTTCATCTTTCGGCAACT }\end{array}$ \\
\hline $\begin{array}{l}\text { Donor } \\
\text { Template C }\end{array}$ & $83.6^{\circ} \mathrm{C}$ & $\begin{array}{l}\text { TAATATGGACTAAAGGAGGCTTTTCTGGAGGTCAATCTATATAAAATCGTTCTCA } \\
\text { ATGATTAAAATAGCATAGTCGGGTGTTTCTATTAGTCTCAGCGTTCCGTAACA }\end{array}$ \\
\hline $\begin{array}{l}\text { Donor } \\
\text { Template D }\end{array}$ & $83.4^{\circ} \mathrm{C}$ & $\begin{array}{l}\text { TAATACGGACTTAAGGACGCTTTGCTGCATGTCGACCTAAAAAAATTTGTTTTGA } \\
\text { ATGAGTAAAATAGCATAGTCGGGTTTTTCTTTTAGTTTCAGCTTTCCGCAACA }\end{array}$ \\
\hline $\begin{array}{l}\text { Donor } \\
\text { Template E }\end{array}$ & $82.0^{\circ} \mathrm{C}$ & $\begin{array}{l}\text { TAATATGGACTAAAGGAGGCTTTTCTGGAGGTCCATCTAGATAAACTCGTTATCA } \\
\text { ATAATTAATATAGCCTAGTCTGGTTTGTCTTTTAGTTTCAGCTTTCCGCAACA }\end{array}$ \\
\hline $\begin{array}{c}\text { Donor } \\
\text { Template F }\end{array}$ & $80.4^{\circ} \mathrm{C}$ & $\begin{array}{l}\text { TAATAAGGACTCAAGGACGCTTTGCTGCAAGTCGATCTAAATAAATTCGTTTTCA } \\
\text { ATAATTAATATAGCCTAGTCTGGTTTGTCTTTTAGTTTCAGCTTTCCGCAACA }\end{array}$ \\
\hline
\end{tabular}


Table 3. Primers used in this study

\begin{tabular}{|c|c|c|}
\hline $\begin{array}{l}\text { Primer } \\
\text { Name }\end{array}$ & Sequence & Primer Description \\
\hline DG31 & GGAACGTGCTGCTACTCATC & $\begin{array}{l}\text { Anneal to the start of URA3 allele to } \\
\text { screen URA }{ }^{+} \text {colonies }\end{array}$ \\
\hline DG32 & TTGCTGGCCGCATCTTCTCA & $\begin{array}{l}\text { Anneal to the end of URA3 allele to } \\
\text { screen URA }{ }^{+} \text {colonies }\end{array}$ \\
\hline DG191 & CCCTTTCGTCTCGCGCGTTT & $\begin{array}{l}\text { Amplify gBlock donor to build A-F } \\
\text { strains }\end{array}$ \\
\hline DG192 & GCTCTGTTATAAATAATACC & $\begin{array}{l}\text { Amplify gBlock donor to build A-F } \\
\text { strains (Reverse) }\end{array}$ \\
\hline DG319 & $\begin{array}{c}\text { ATGGGAACCATAAGCTGGACACATTTCTTGAGGTT } \\
\text { CTGATGCGGTATTTTCTCCTTACGC }\end{array}$ & $\begin{array}{c}\text { Integrate constructs with divergent } \\
\text { mismatch distribution downstream of } \\
\text { FAU1 (Reverse) }\end{array}$ \\
\hline DG320 & $\begin{array}{c}\text { CGAGAAAGGCACTCTCTCACTGAAAAGTAATGAAA } \\
\text { TAATAAGGACTCAAGGACGCTTTGC }\end{array}$ & $\begin{array}{l}\text { Integrate donor sequence from bRA29 } \\
\text { plasmid with gBlock for A }\end{array}$ \\
\hline DG321 & $\begin{array}{c}\text { CGAGAAAGGCACTCTCTCACTGAAAAGTAATGAAA } \\
\text { TAATATGGACTAAAGGAGGCTTTTC }\end{array}$ & $\begin{array}{l}\text { Integrate donor sequence from bRA29 } \\
\text { plasmid with gBlock for } E \text { and B }\end{array}$ \\
\hline DG322 & $\begin{array}{c}\text { CGAGAAAGGCACTCTCTCACTGAAAAGTAATGAAA } \\
\text { TAATACGGACTTAAGGACGCTTTGC }\end{array}$ & $\begin{array}{l}\text { Integrate donor sequence from bRA29 } \\
\text { plasmid with gBlock for B }\end{array}$ \\
\hline DG326 & AATGTGCTCCACCATCACAG & $\begin{array}{c}\text { Anneal } 798 \text { bp upstream of FAU1 to } \\
\text { confirm integration of divergent } \\
\text { constructs }\end{array}$ \\
\hline DG327 & CAGGCCTTTGATGGAATCAG & $\begin{array}{c}\text { Anneal 314bp upstream of FAU1 to } \\
\text { confirm integration of divergent } \\
\text { construct }\end{array}$ \\
\hline $\mathrm{JC} 1$ & CCAGCGAAGACTGTCGTATCGTTTT & gRNA1 to target FAU1 \\
\hline $\mathrm{JC2}$ & GATACGACAGTCTTCGCTGGGATCA & gRNA 2 to target FAU1 \\
\hline $\mathrm{JC} 14$ & $\begin{array}{l}\text { CCCTTTCGTCTCGCGCGTTTCGGTGATGACGGTGAAAA } \\
\text { CCTCTGACACATGCAGCTAATAAGGACTGAAG }\end{array}$ & $\begin{array}{l}\text { Integrate donor sequence from bRA29 } \\
\text { plasmid with gBlock for } F\end{array}$ \\
\hline JC15 & $\begin{array}{l}\text { TGCTCTGTTATAAATAATACCATTTGTTAGTAAAAATT } \\
\text { CGAGCTCGGTACCCGGGTGTTGCGGAAAGCTG }\end{array}$ & $\begin{array}{l}\text { Integrate donor sequence from bRA29 } \\
\text { plasmid with gBlock for } F\end{array}$ \\
\hline JC16 & $\begin{array}{l}\text { CCCTTTCGTCTCGCGCGTTTCGGTGATGACGGTGAAAA } \\
\text { CCTCTGACACATGCAGCTAATATGGACTAAAG }\end{array}$ & $\begin{array}{l}\text { Integrate donor sequence from bRA29 } \\
\text { plasmid with gBlock for C }\end{array}$ \\
\hline $\mathrm{JC} 17$ & $\begin{array}{l}\text { TGCTCTGTTATAAATAATACCATTTGTTAGTAAAAATT } \\
\text { CGAGCTCGGTACCCGGGTGTTACGGAACGCTG }\end{array}$ & $\begin{array}{l}\text { Integrate donor sequence from bRA29 } \\
\text { plasmid with gBlock for C (Reverse) }\end{array}$ \\
\hline
\end{tabular}


Table 4. Plasmids used in this study

\begin{tabular}{|c|c|}
\hline $\begin{array}{c}\text { Plasmid } \\
\text { Name }\end{array}$ & \multicolumn{1}{c|}{ Plasmid Description } \\
\hline bRA25 & $\begin{array}{r}\text { pRS314-based plasmid containing the 5' sequences from the URA3 gene (UR), an } \\
\text { artificial split-intron with the splice-donor site (5' SD) and the HO recognition site (HOcs) }\end{array}$ \\
\hline bRA29 & $\begin{array}{r}\text { pRS314-based (CEN4; TRP1) plasmid containing the 3' splice-acceptor of the intron, the } \\
\text { 3' sequence from the URA3 gene (A3), and the TRP } 1 \text { marker }\end{array}$ \\
\hline
\end{tabular}

487 
bioRxiv preprint doi: https://doi.org/10.1101/2022.01.30.478419; this version posted January 31, 2022. The copyright holder for this preprint (which was not certified by peer review) is the author/funder, who has granted bioRxiv a license to display the preprint in perpetuity. It is made available under aCC-BY 4.0 International license.

Figure 1.
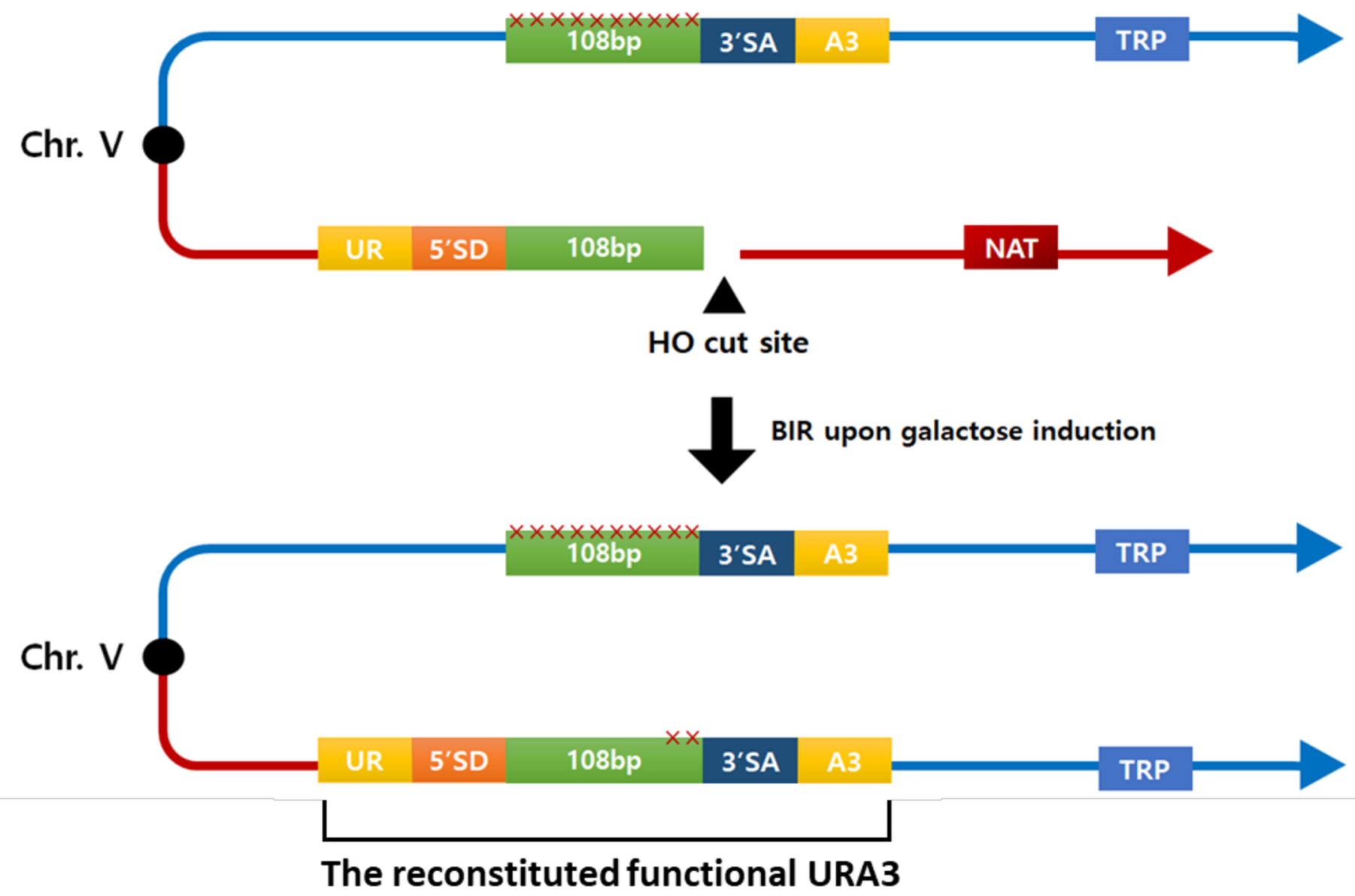

$$
\begin{aligned}
& \mathbf{X}=\text { Mismatch } \\
& \text { 5'SD = Splice Donor } \\
& \text { 3'SA = Splice Acceptor }
\end{aligned}
$$


Figure 2.

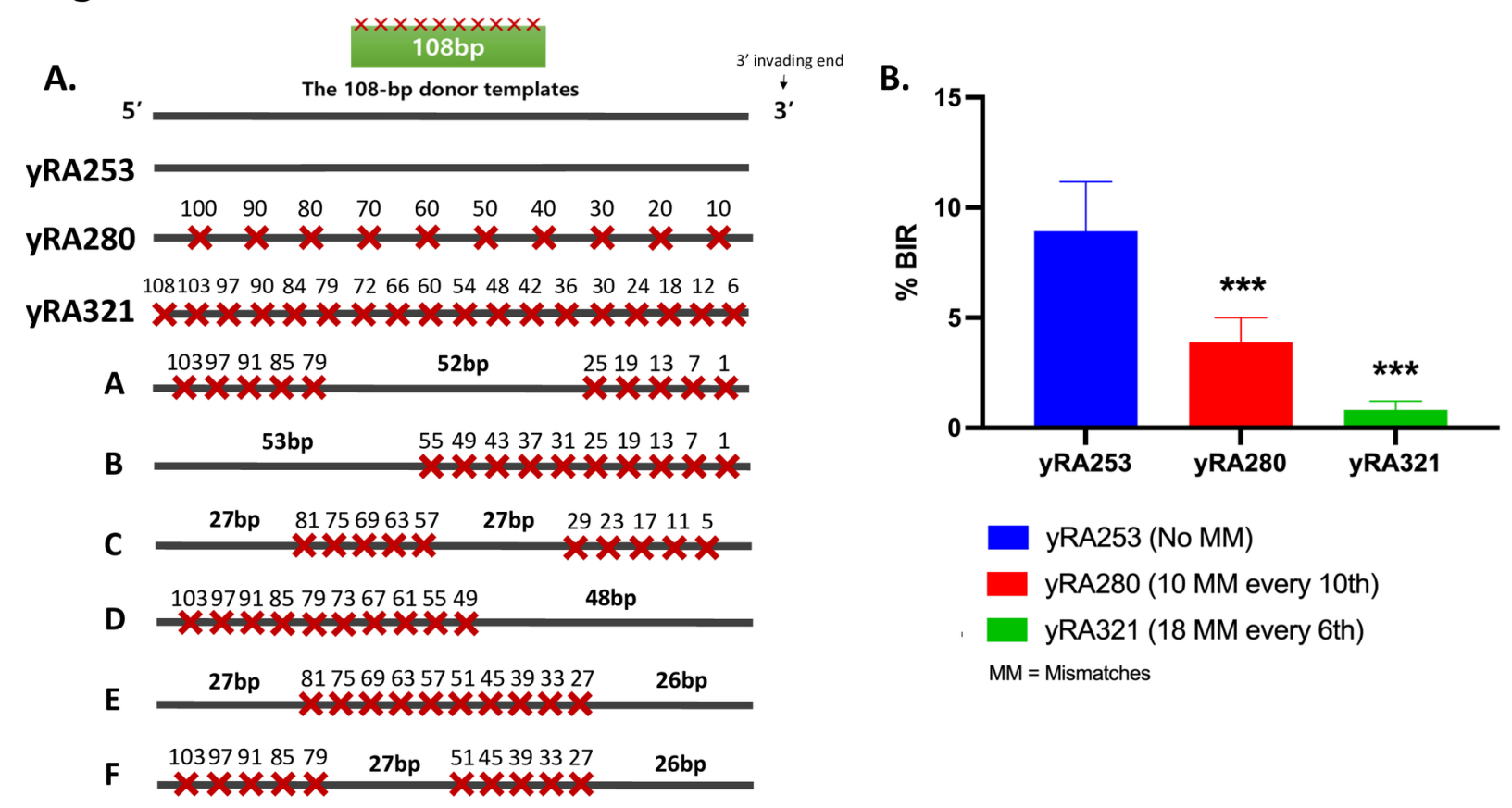

c.
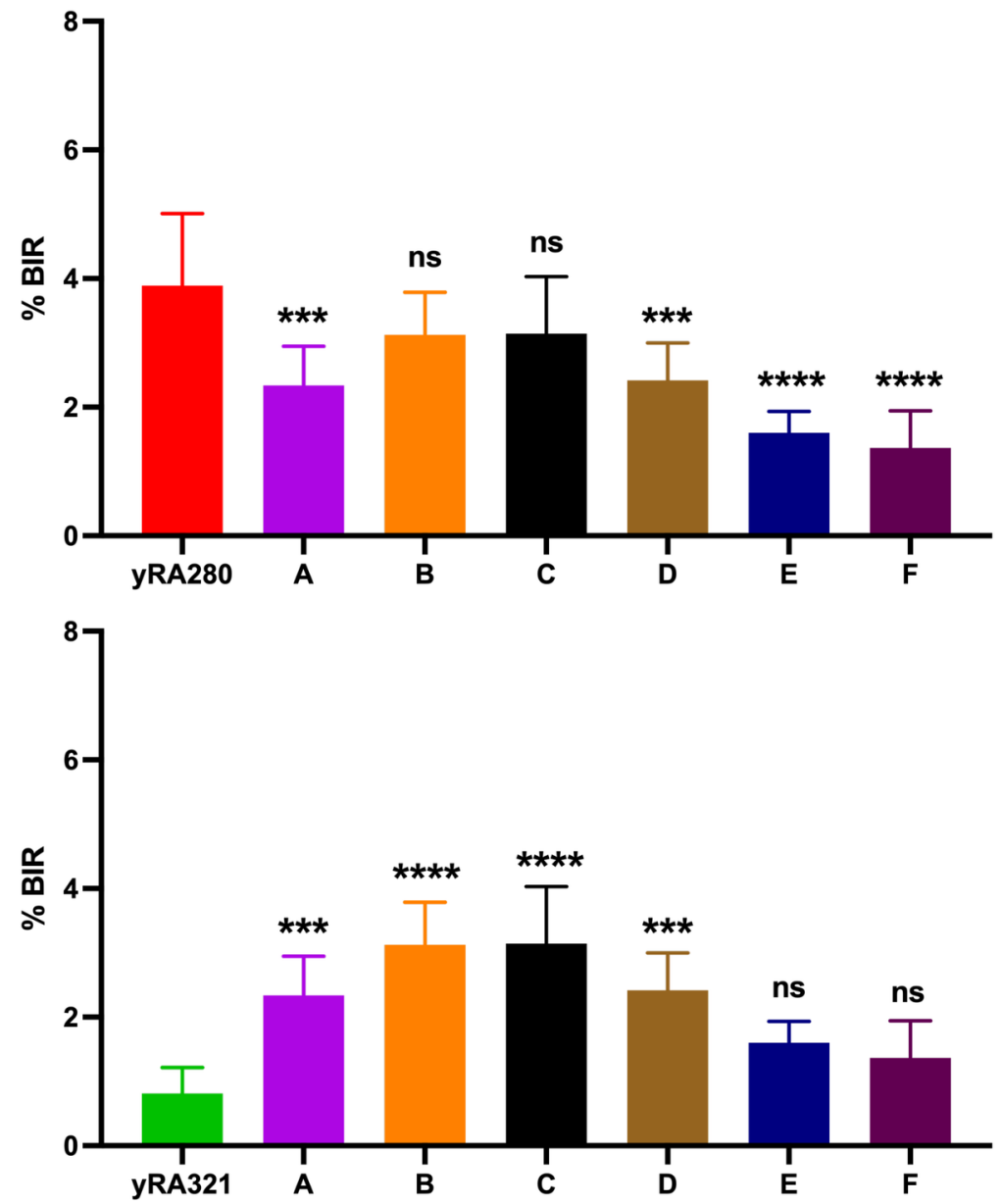


\section{Figure 3.}

A.

\section{\%BIR vs Tm : WT}

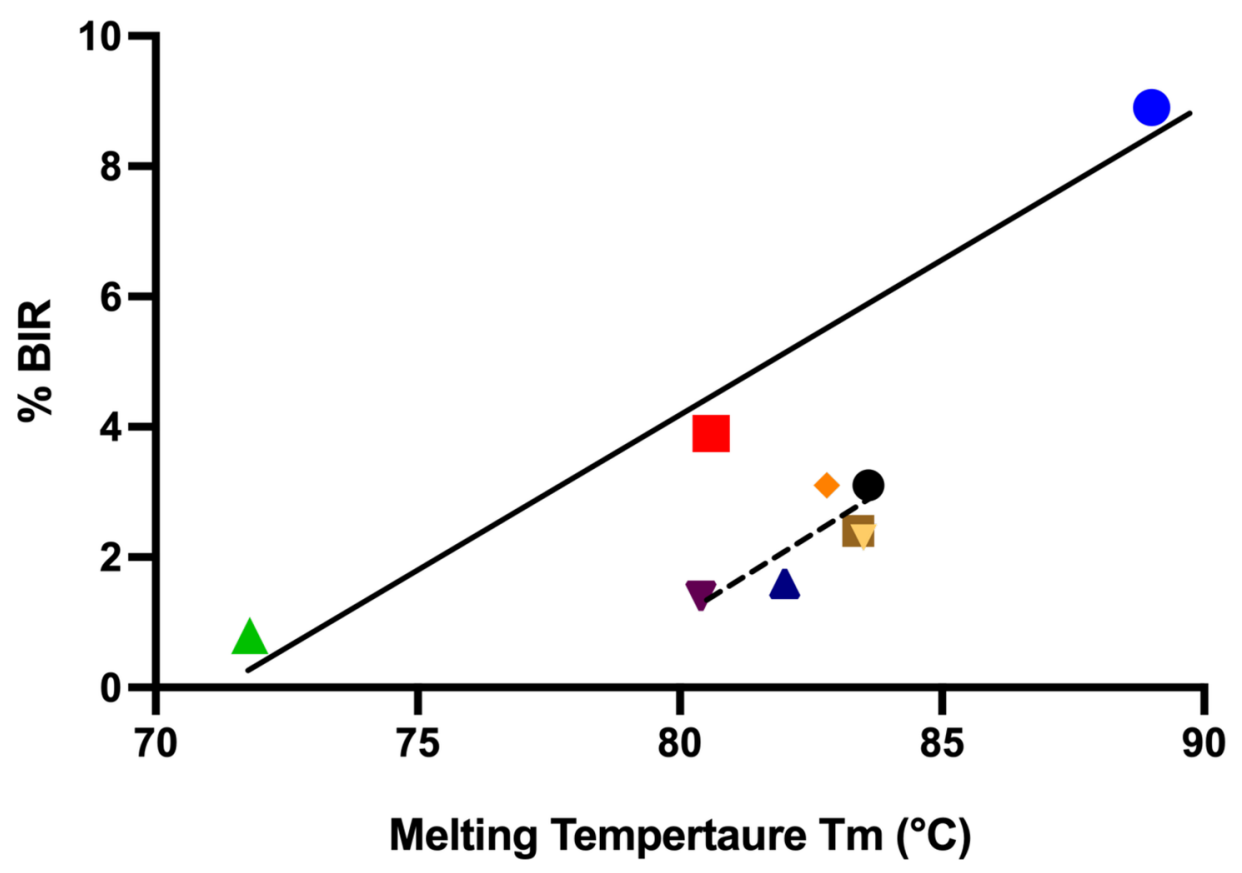

yRA253

- yRA280

- yRA321

$\nabla \mathrm{A}$

$\rightarrow B$

- C

D

$\Delta \mathrm{E}$

$\nabla \mathrm{F}$

B.
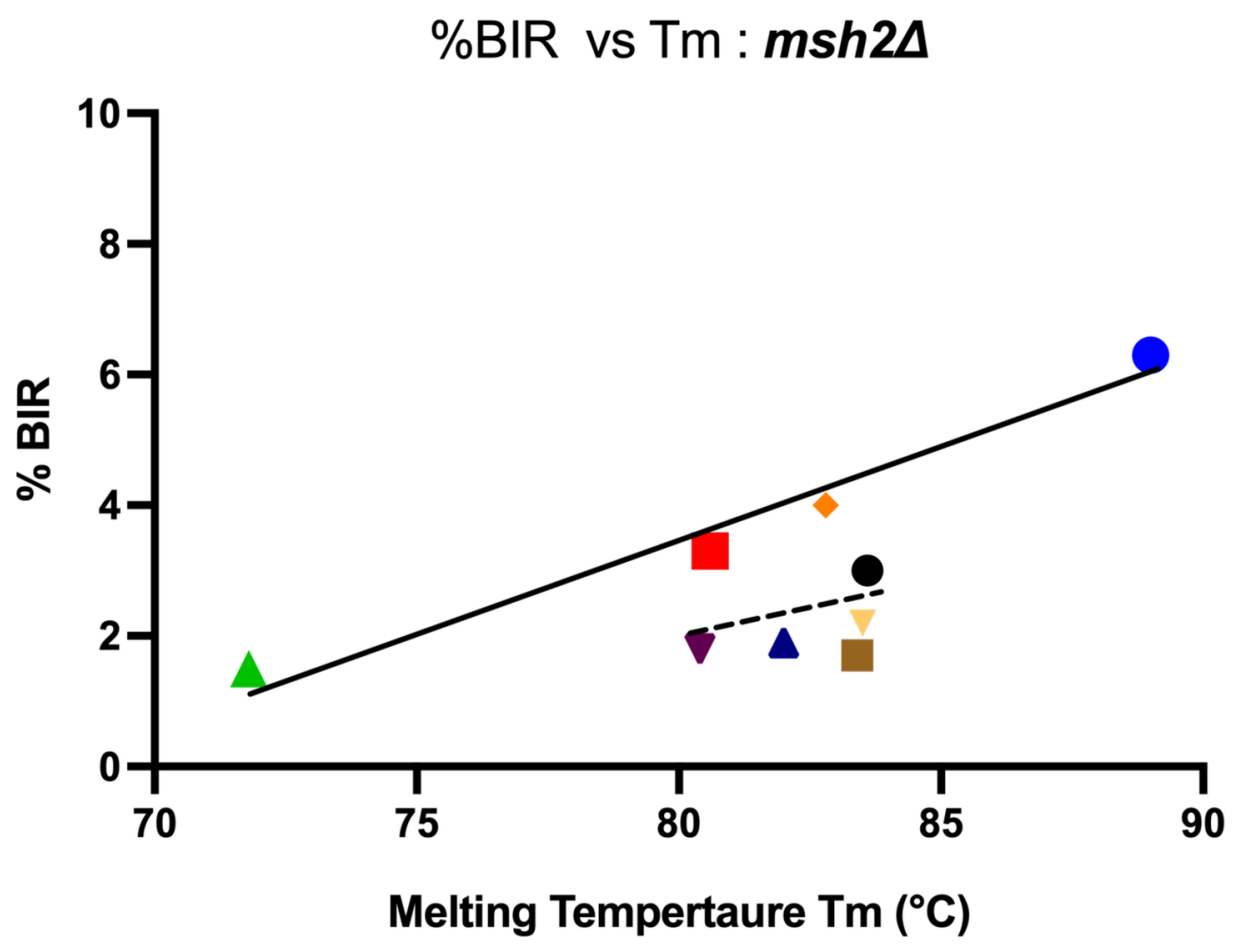

yRA253 yRA280

$\triangle \quad \mathrm{yRA321}$

$\nabla \mathrm{A}$

$\checkmark B$

- C

D

$\Delta \mathrm{E}$

$\nabla \mathrm{F}$

Melting Tempertaure $\mathrm{Tm}\left({ }^{\circ} \mathrm{C}\right)$ 


\section{Figure 4.}

A.

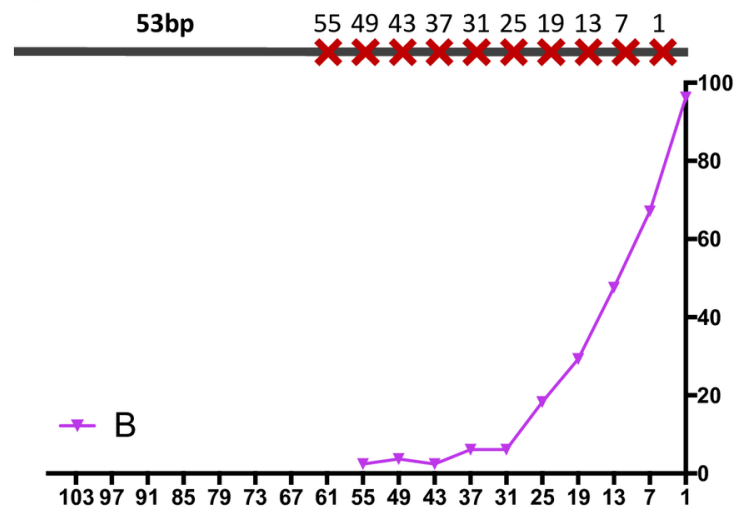

C.

MM Position

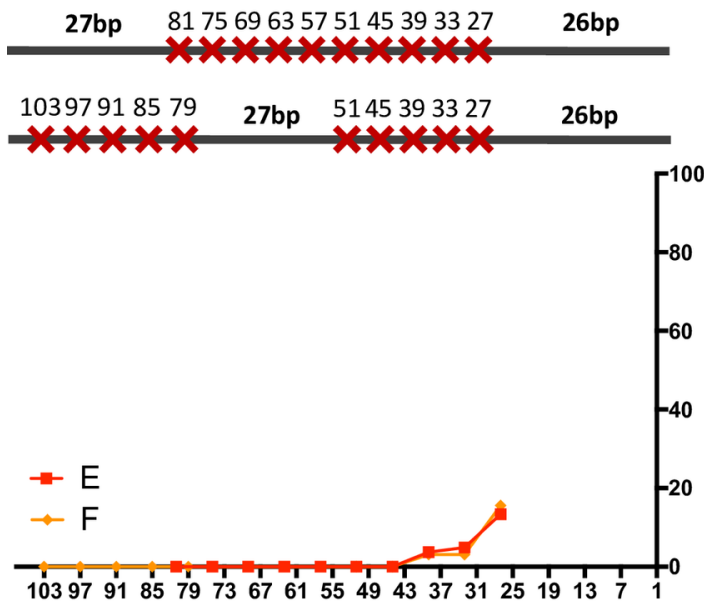

MM Position
B.

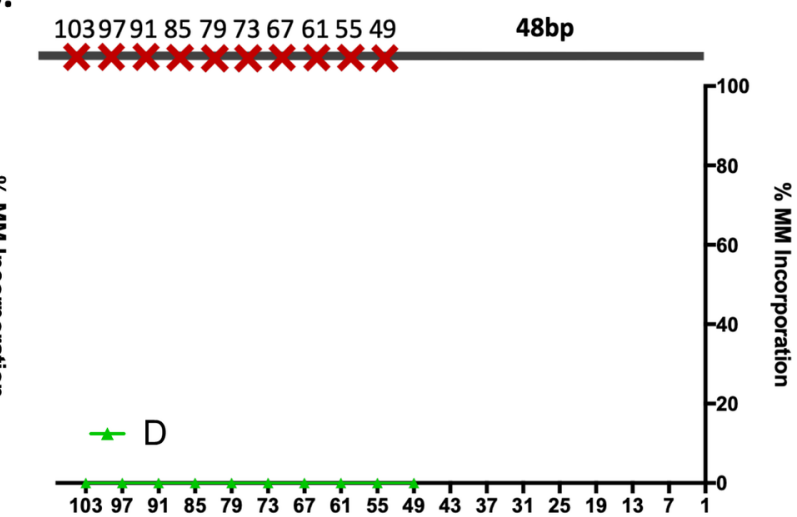

D.

MM Position

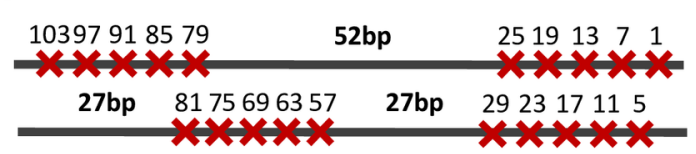

$\rightarrow A$

$\rightarrow C$

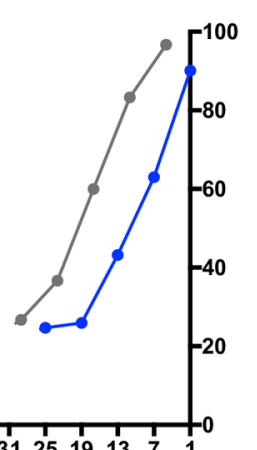

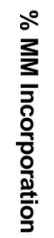

E.

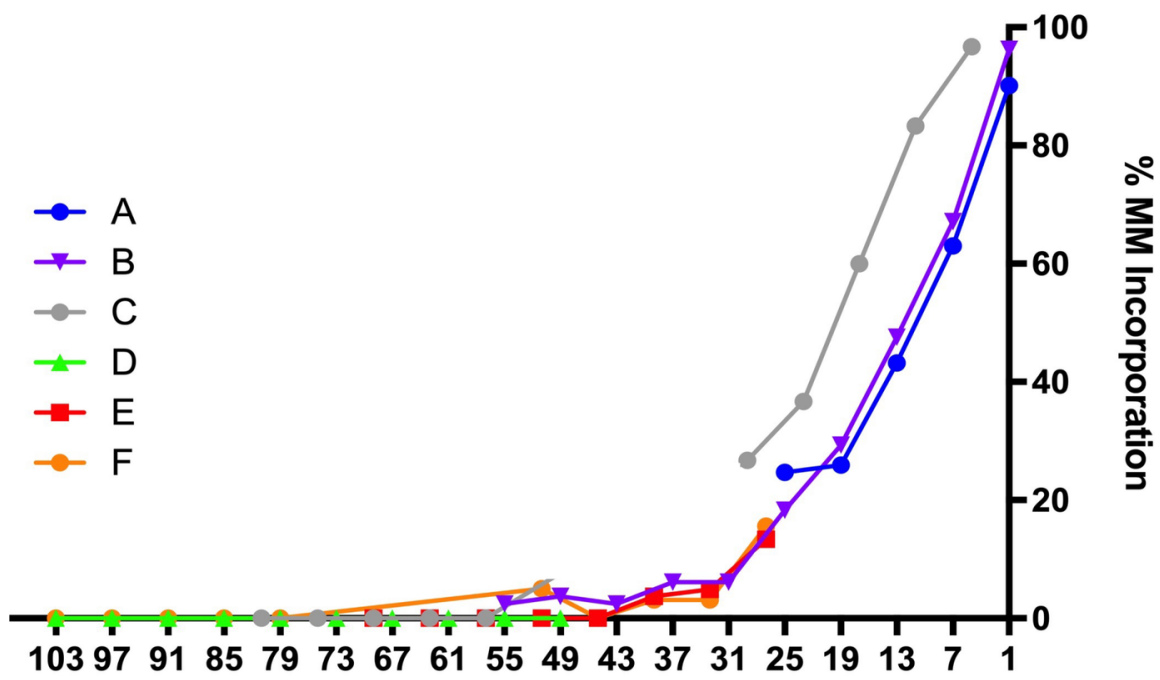

MM Position 
Figure 5.

YRA280

A.

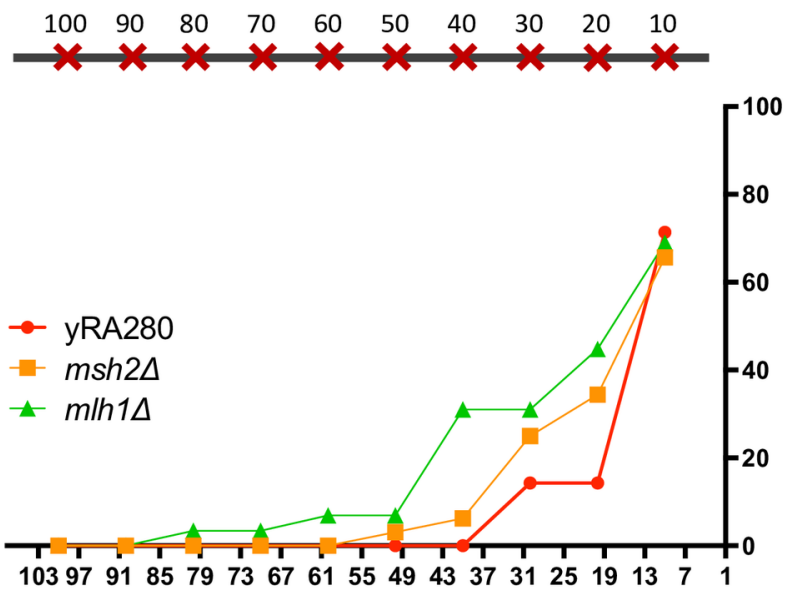

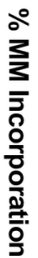

MM Position

YRA321

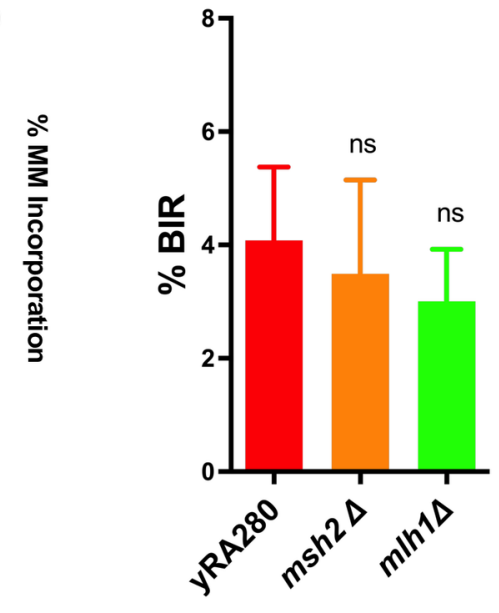

$1081039790847972666054484236 \quad 30241812 \quad 6$
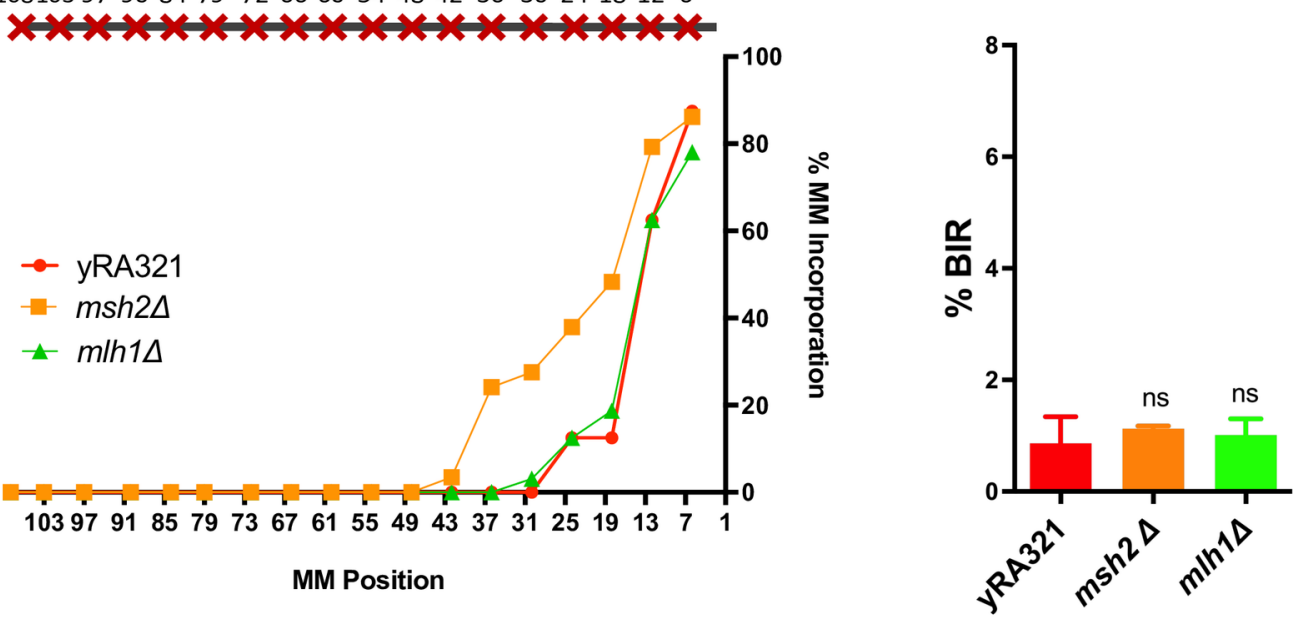

MM Position

Donor template A

B.
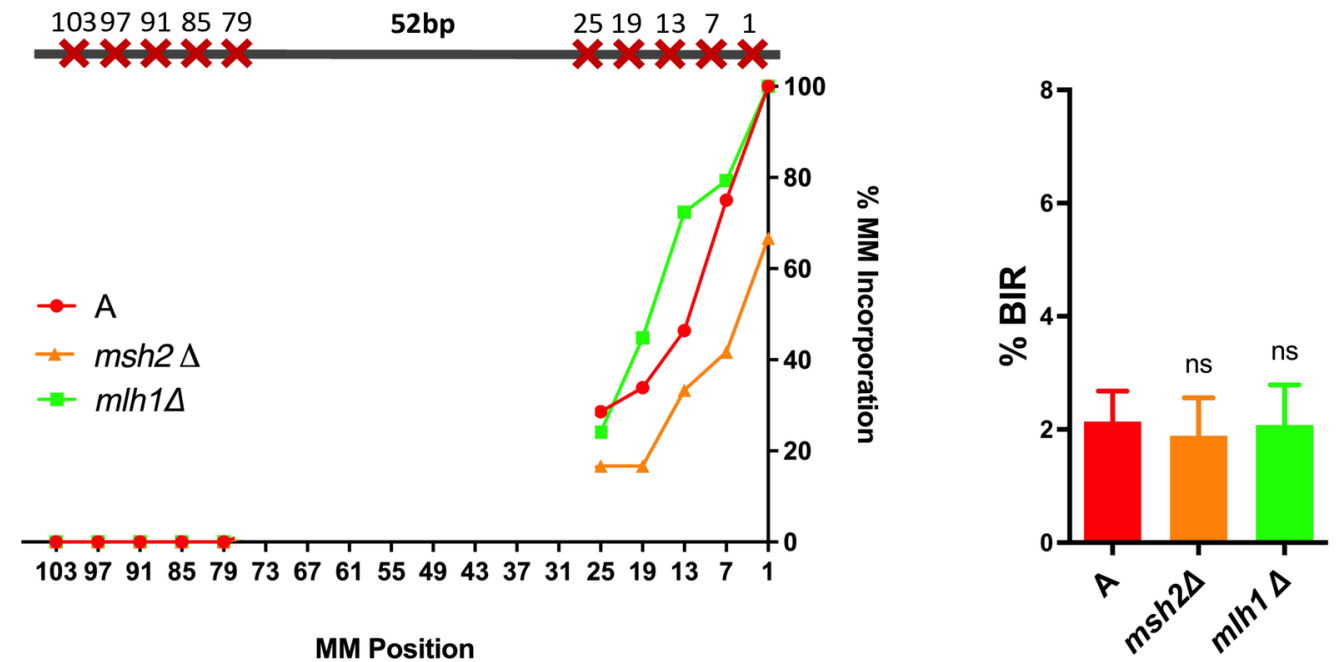

MM Position 
Figure 5 (continued).
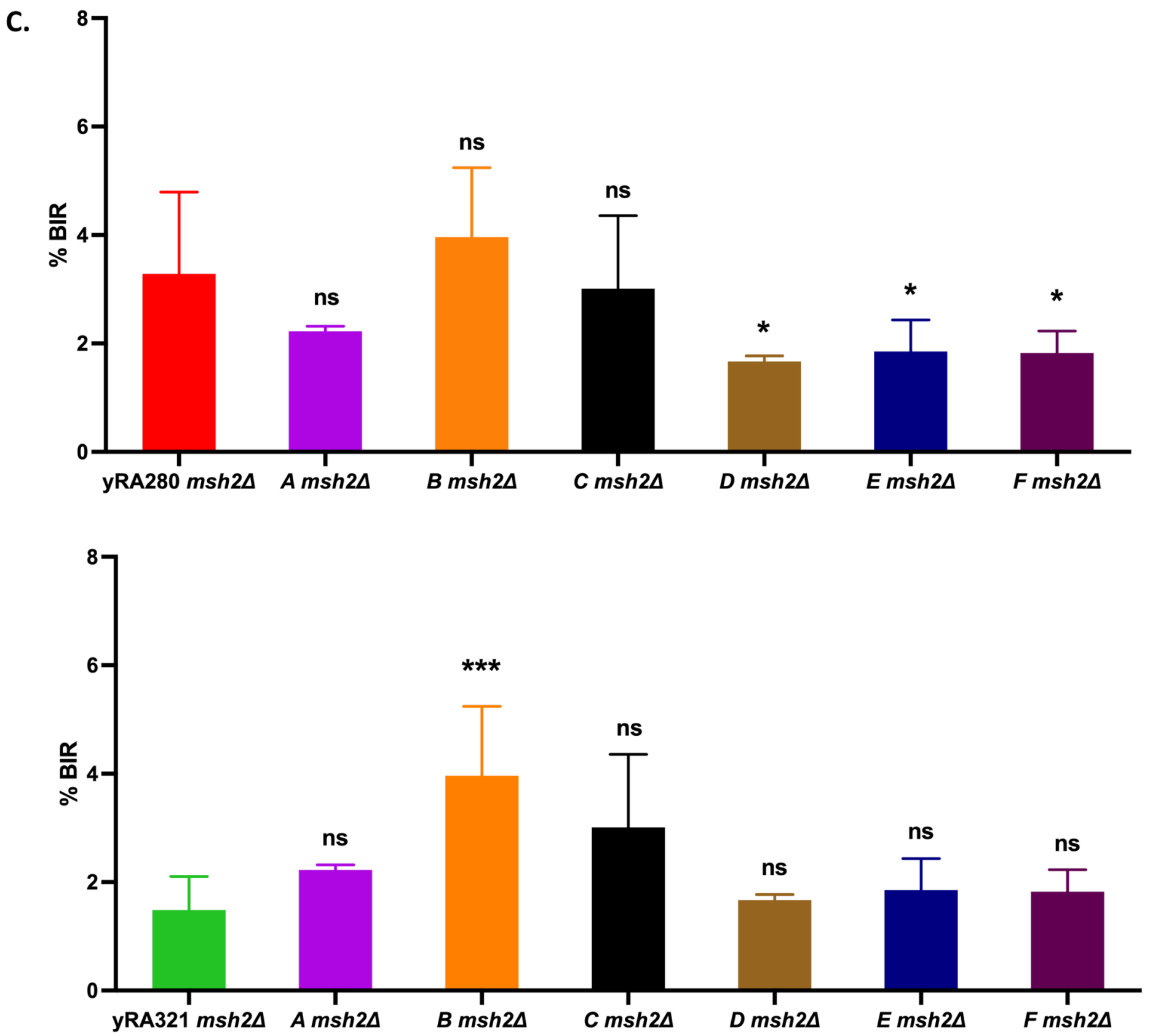


\section{Figure S1.}
A.
RPA (Replication Protein A)
$\triangle$ Rad52
Rad51
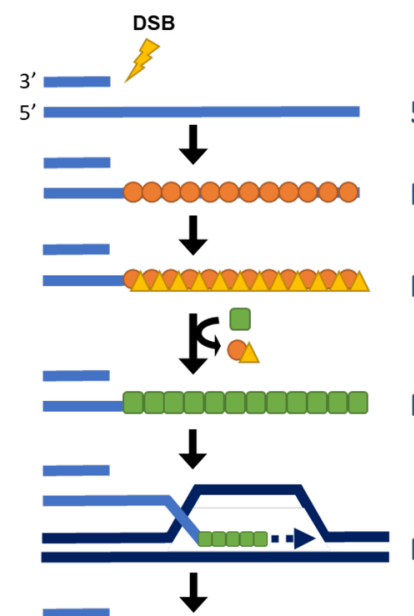

Rad52 promote Rad51 to displace RPA

RPA binds to the 3' ssDNA tails of the resected DSB

Rad52 binds to the RPA-ssDNA complex

Rad51 catalyzes DNA strand invasion to form a D-loop Initiation of DNA synthesis

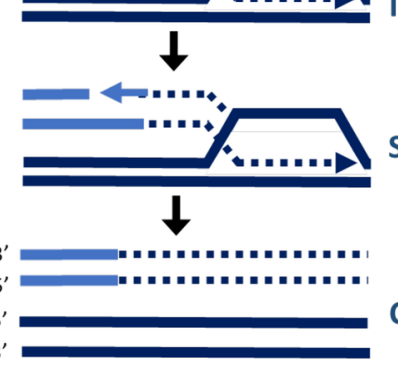

Second-strand DNA synthesis Completion of BIR result nonreciprocal translocations

B.

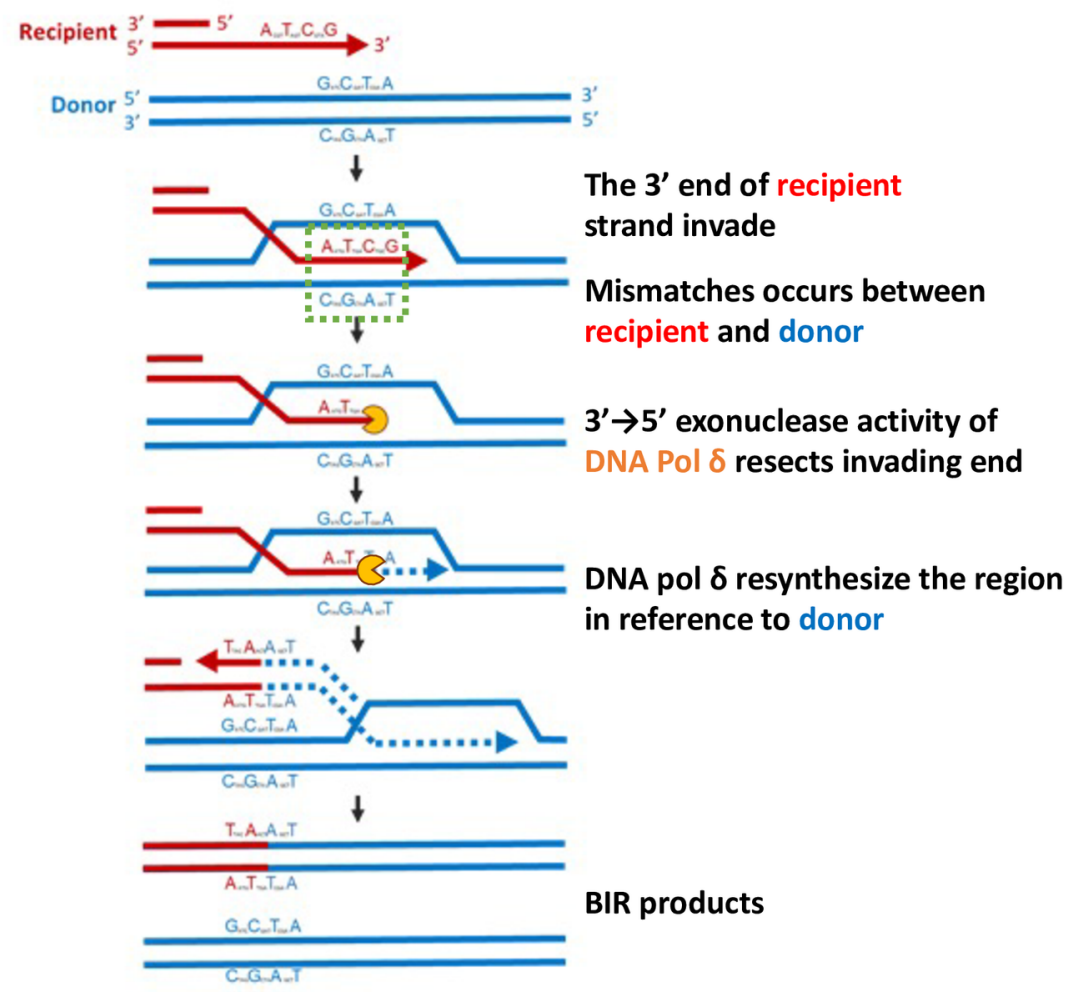


bioRxiv preprint doi: https://doi.org/10.1101/2022.01.30.478419; this version posted January 31, 2022. The copyright holder for this preprint (which was not certified by peer review) is the author/funder, who has granted bioRxiv a license to display the preprint in perpetuity. It is made available under aCC-BY 4.0 International license.

\section{Figure S2.}

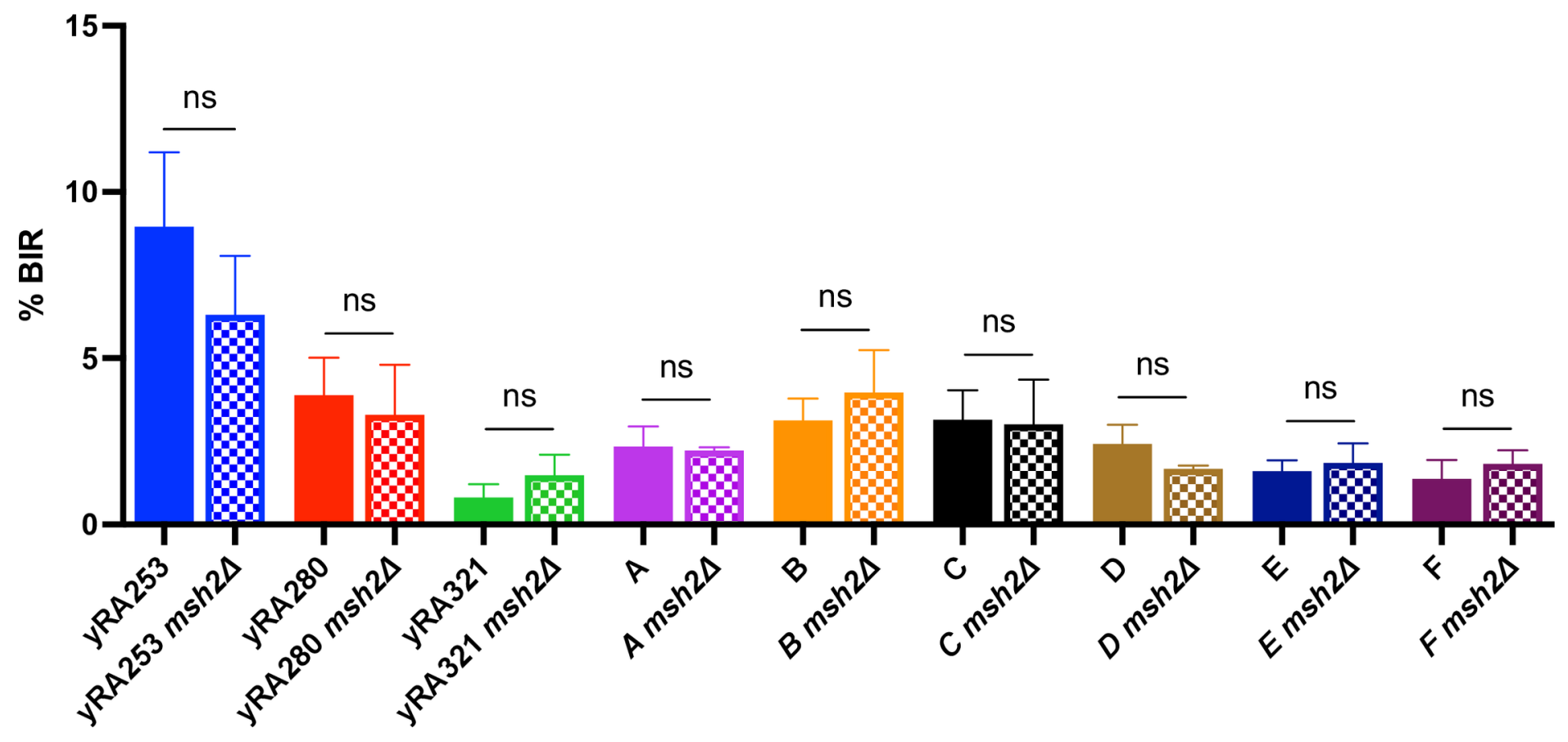

